\title{
TOTAL-FACTOR ENERGY EFFICIENCY OF REGIONS IN CHINA CONSIDERING NATURAL DISASTER EFFECTS
}

\author{
LIU, C. N. ${ }^{*}$-ZHANG, L. Y. - LIU, Y. Q. \\ School of management, Nanchang University, Nanchang 330031, China \\ *Corresponding author \\ e-mail:pan81706@163.com \\ (Received 22 $2^{\text {nd }}$ Jul 2016; accepted $9^{\text {th }}$ Nov 2016)
}

\begin{abstract}
This paper analyzed total-factor energy efficiency (TFEE) of 30 regions in China during the period of 2004-2010, considering natural disasters effects. Based on the input-oriented data envelopment analysis (DEA), the paper computes the total-factor energy efficiency of 30 regions in China and the relationship among three main regional area of China, the east area, the middies and the west. The paper also further explored the total-factor energy efficiency by using Malmqusit index to find out the main factor of it and proposed improvement advices based on the analysis. The empirical results of the paper indicate that the total-factor energy efficiency of China in the period is decreasing and that of different regions has varies changes during the period; the total-factor energy efficiency of three main areas is also different with each other but has the trend of convergence. The paper also came to the conclusion that technical change is a double-edged sword, which makes less contribution to total factor energy efficiency compared to ignoring the effects. Thus, the government needs to make reasonable use of technology to minimise the negative effects and increase investment in technology science and encourage technological innovation, thus really improve the energy efficiency in China.
\end{abstract}

Keywords: energy use efficiency; disaster influence; data envelopment analysis; Mamlqusit index; regional comparison

\section{Introduction}

In order to implement the strategy of sustainable development, the government of China proposed a development concept of building a resource-saving and environmentfriendly society. As we all know, modernization development is inseparable from the support of energy which has an important influence on the development of all countries in the world. Energy as essential production factor to the economic development process, in promoting social development, it's unreasonable use and excessive consumption had on negative impact on environment and society, such as environmental pollution, energy disputes and the problem of frequently occurred natural disasters. At present, countries are faced with the needs and challenges of development, increasing energy demand. Problems caused by energy such as its supply and demand contradiction, energy disputes, environmental pollution and frequently occurred natural disasters are becoming increasingly acute, and therefore utilization of energy once again become focus and topics of the government, environmental organizations, the media and experts of different organizations and individuals in order to find solutions to conflicts between energy and crisis, and find the most efficient way to improve use efficiency of energy. As one of the world's top energy consuming countries, the Chinese government gradually guide the extensive changes in corporate energy consumption habits, and gradually form a lean style energy consumption habits. Thus, how to make better use of energy to improve energy efficiency has become the focus of public attention.

The current study on energy efficiency mainly includes single-factor and total-factor studies on it, in which single-factor energy efficiency study focus on effective output 
and energy input of an economy investment, commonly used indicators of productivity and energy consumption per unit of GDP, such as Samuels (1984), Newell et al. (1998) and other studies of the effects of single-factor energy efficiency adjustment of industrial structure on energy efficiency. Total Factor Energy efficiency is based on total factor productivity theory to determine the production function, reflecting the substitution effect between the input elements to reveal impact of a regional resource endowments of their energy efficiency, and its essence is to computing energy efficiency based on the determination of energy efficiency frontier and the ratio of the actual energy efficiency to its frontier.

There are two ways to determine the forefront of energy efficiency: First, use parameter estimation to compute energy efficiency according to the pre-set function and its error term, the commonly used parametric methods include stochastic frontier analysis (SFA), distribution free approach (DFA) and thick frontier approach (TFA). Second, nonparametric methods, through the weight calculations of input and output indicators of decision-making unit to determine the efficiency frontier, and to determine energy efficiency according to the relative distance of each decision-making unit with the efficiency frontier, the commonly used non-parametric methods include data envelopment analysis (DEA) and index method, among which DEA is the most commonly used and effective method in studies of energy efficiency.

As to studies on total-factor energy efficiency, there are numbers of researches study on the topic using DEA method, such as Boyd and Pang (2000) calculated the energy efficiency measured by DEA, and proposed that total-factor productivity improvement would improve energy efficiency. Mukherjee (2008) analyzed the energy efficiency of the manufacturing sector in US with data of manufacturing enterprises for empirical analysis with DEA metod. Azadeh et al. (2007) analyzed the total energy efficiency of sub-sectors of some OECD (Organization for Economic Cooperation and Development) countries, and the utilization of DEA for total energy efficiency assessment and consumption optimization of energy intensive manufacturing sectors. Martinez (2011) measured energy efficiency development in non-energy-intensive sectors (NEISS) in Germany and Colombia from a production-based theoretical framework using DEA method with data from the German and Colombian Annual Surveys of Industries from 1998 to 2005. Cui et al. (2014) calculated the energy efficiencies of nine countries during 2008-2012 by using DEA method and Malmquist index choosing number of employees in energy industry, energy consumption amount and energy services amount as the inputs while $\mathrm{CO}_{2}$ emissions per capita and industrial profit amount are chosen as the outputs. As to total factor energy efficiency, Hu and Wang (2006) was the first that used DEA method to analyze total-factor energy efficiencies of 29 administrative regions in China for the period 1995-2002 by employing data envelopment analysis (DEA)with labor, capital stock, energy consumption, and total sown area of farm crops used as a proxy of biomass energy as the four inputs and real GDP as the single output, and defined total-factor energy efficiency as the ratio of the target energy input that is suggested from DEA to the actual energy inputs in a region. Other scholars, such as Honma and $\mathrm{Hu}$ (2008) computed the regional total-factor energy efficiency (TFEE) in Japan by employing the DEA method, using labor employment, private, and public capital stock) and 11 energy sources as input while using GDP as it sole output, who will labor, capital, and 11 kinds of energy as input variables, the GDP total factor studied energy issues in Japan as the output variable. Vlahinic-Dizdarevic and Segota (2012) examined the economy-wide energy efficiency changes in the EU countries in 
the period from 2000 to 2010 and compared the results with the traditional energy efficiency indicator by using the DEA CCR multiple input-oriented model in order to analyze the efficiency of the use of three inputs (capital stock, labor and energy consumption) in producing GDP as the output. Zhang and Cheng (2011) used a totalfactor framework to investigate energy efficiency in 23 developing countries during the period of 1980-2005 to explore the total-factor energy efficiency and change trends by applying data envelopment analysis (DEA) window of these countries.

Many researchers study the energy efficiency in China following the research method of $\mathrm{Hu}$ and Wang (2006) on energy efficiency, analyzing total-factor energy efficiency of regions in China, and building total-factor energy efficiency indicators which include labor and capital storage, energy consumption, expected output and undesired outputs. For example, Fan and Zhou (2012) referring to Hu and Wang's (2006) research ideas, calculated total-factor energy efficiency in various regions of China based on DEA method while considering environmental pollution as undesirable output. Zou et al. (2013) measured and evaluated regional energy efficiency in China based on provincial panel data using DEA method. Some of these studies are basically only consider the expected output as a single output indicator such as GDP, some consider the external environment, such as environmental pollution will be considered undesirable output to study of Chinese provincial energy efficiency, but no papers studies the relationship of between natural disasters total- factor energy efficiency.

The average GDP growth rate of China is 9.6\% since 1990, while the average growth rate of energy consumption is $6.15 \%$, GDP and energy consumption growth trends are shown in Fig. 1. China's economic growth only saw a emporary growth during the period of 1991-1999, but mainly continue its downward trend in the period while the growth rate of energy consumption was low and had a significantly decline in 1995. GDP and energy consumption has a overall consistency increasing trend from the year 1999 to 2007. Affected by top ten large disasters in 2008, China 's GDP and energy consumption growth trends were significantly decreased, but began to grow after this year. In general, China's sustained economic growth and energy consumption closely related with each other while economic growth was promoted with relatively low energy consumption. At the same time, we can see from Fig. 1 that the energy consumption growth in 2003 and 2004 had a greater volatility. According to China's energy consumption elasticity coefficient, as shown in Fig. 2, we can be seen that the value of energy consumption elasticity coefficient is fluctuating but generally less than 1 with its average more than 0.5 , and the values of energy consumption elasticity coefficient of the years 2003 and 2004 are greater than 1, that is energy consumption of these two years is greater than the GDP growth of that year. Thus, we can see that the energy efficiency of China is low, with a fact that lowers than international countries.

Researches on the theme of natural disasters are increasing since 2008, as an influence of China's top ten natural disasters. Fig. 3 is a growth trend chart of the ratio of natural disaster economic loss with that of the previous year, from which we can see that natural disasters overall economic losses continue to growth than its last year, and has its maximum growth rate in 2008. With the connection of this three Figs. 1-3, we can see GDP growth, energy consumption growth and the growth of nature disaster losses have some relevance with each other as all this three have some fluctuations, and the peaks and troughs relevant to each other. Thus, we come to the conclusion that economic growth and energy have a close relationship, and the external environment such as natural disasters will also counterproductive in economic growth and energy use. With the rapid 
economic development and frequently occurred natural disasters of China, we can study on the relationship between natural disaster and energy efficiency to have a better understanding of energy and environment, energy and economic growth, and so on (Kang et al., 2016; Liu, 2013). Thus, what's the specific contact of natural disasters and energy efficiency, how to improve energy efficiency considering the impact of natural disasters, the paper argues that this is a deserving research topic with importance.

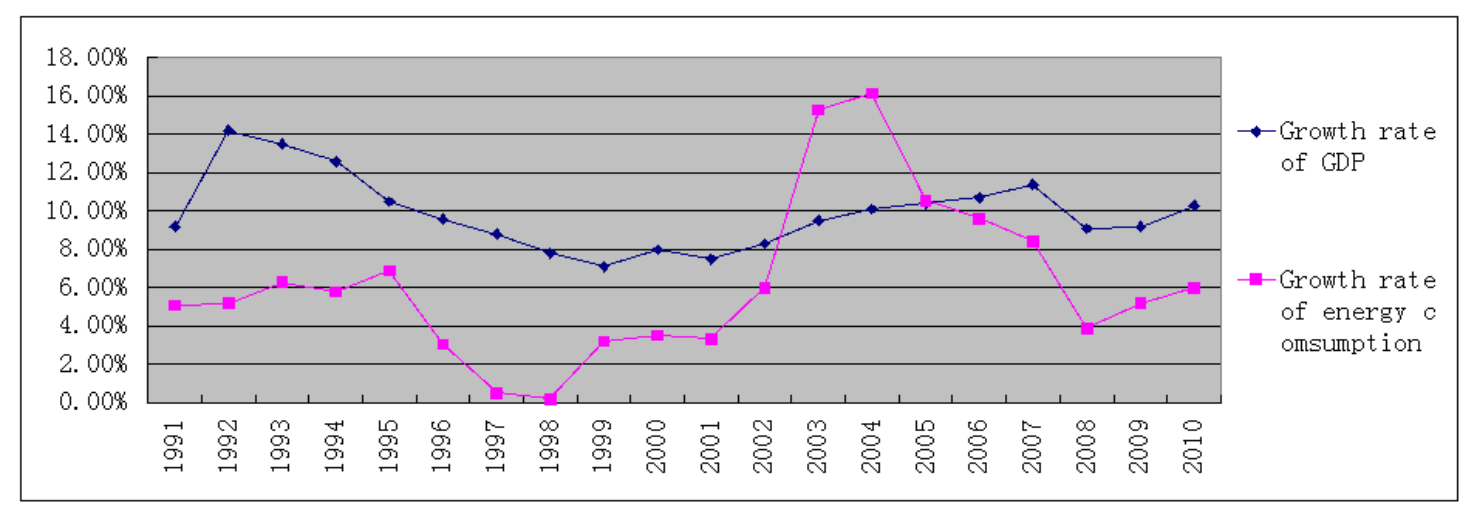

Figure 1. Growth trend charts of GDP and energy consumption

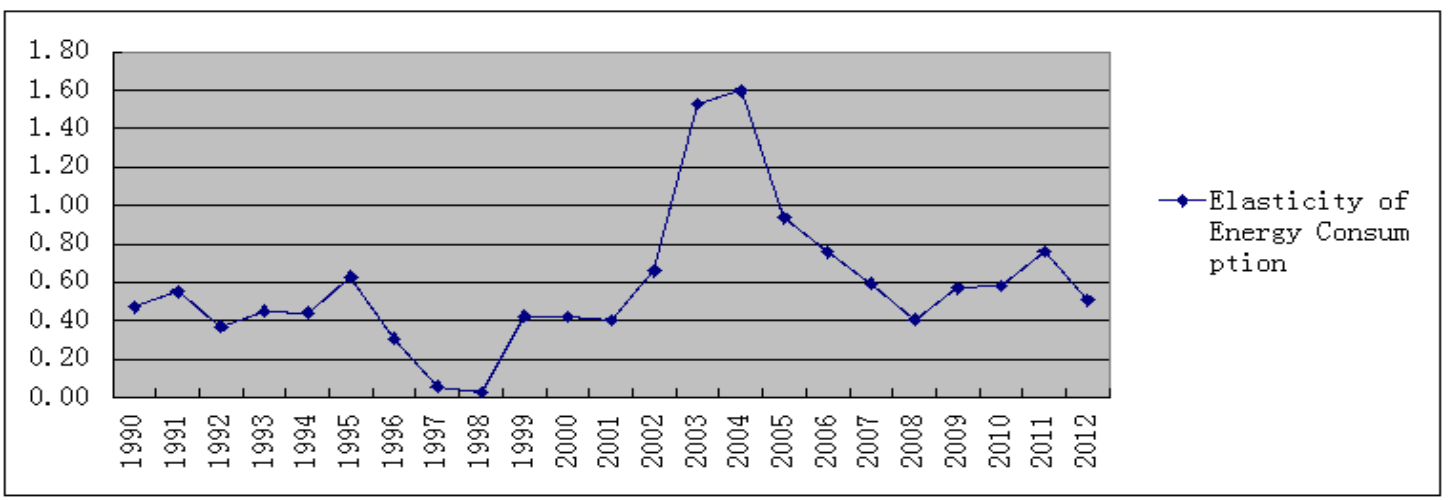

Figure 2. Elasticity of energy consumption

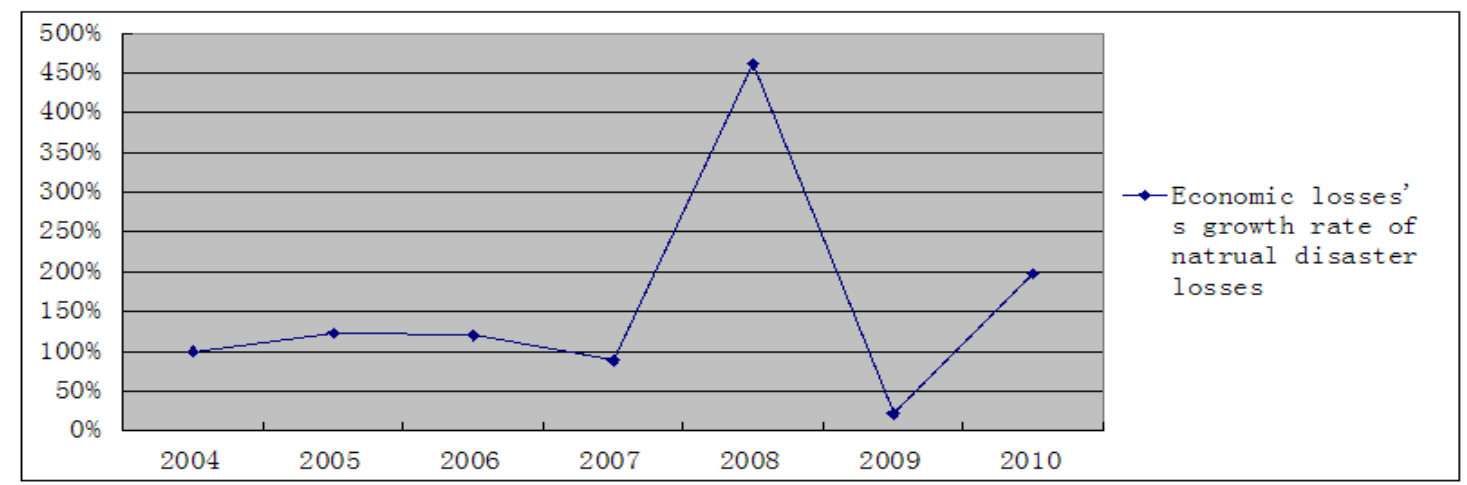

Figure 3. Growth trend chart of natural disasters economic losses 
Based on production theory and DEA method, the paper computes total factor energy efficiency of 30 regions in China considering natural disaster effects, and breaks up the energy efficiency into technical efficiency and technology change to study the main factor that contribute to total factor energy efficiency. By analyzing the total factor energy efficiency (TFEE) of 30 regions in China, to provide reference for China, other developing countries or even the world on energy-related decisions.

\section{Method and data description}

\section{DEA Method}

DEA method is a system analysis method based on non-parametric theory which was proposed by Farrell (1957), and the method assess the efficiency of DMU by applying mathematical linear programming, that is to identify the most efficient point on the frontier as a target for that inefficient DMUs to achieve through mathematical linear programming (Coelli, 1996). DMU on the frontier is efficient while that below the frontier is inefficient, thus, if define the collection of input, desired output and undesired output as $\mathrm{x}=\left(\mathrm{x}_{1 \mathrm{n}}, \mathrm{x}_{2 \mathrm{n}}, \mathrm{x}_{3 \mathrm{n}}, \ldots, \mathrm{x}_{\mathrm{kn}}\right), \mathrm{y}=\left(\mathrm{y}_{1 \mathrm{n}}, \mathrm{y}_{2 \mathrm{n}}, \mathrm{y}_{3 \mathrm{n}}, \ldots, \mathrm{y}_{\mathrm{mn}}\right), \mathrm{z}=\left(\mathrm{z}_{1 \mathrm{n}}, \mathrm{z}_{2 \mathrm{n}}, \mathrm{z}_{3 \mathrm{n}}, \ldots, \mathrm{Z}_{\mathrm{un}}\right)$, its production function can be expressed as:

$$
F(x)=\{(y, z) ; x \rightarrow(y, u)\}
$$

Where $n$ is the number of DMU, $k$ is the number of input elements, $m$ is the number of desired outputs, $u$ is the number of undesired output. Based on CCR DEA method, the paper calculates TFEE of 30 regions in China while take natural disaster effects as undesired output. Based on input-oriented constant returns to scale DEA model can be expressed as follows:

$$
\begin{aligned}
& \boldsymbol{O}^{*}=\min \theta \\
& \text { S.T. }\left\{\begin{array}{l}
\sum_{n=1}^{n} \lambda_{n} x_{k n} \leq \theta x_{0} \\
\sum_{n=1}^{n} \lambda_{n} y_{m n} \leq y_{0} \\
\sum_{n=1}^{n} \lambda_{n} z_{u n} \leq z_{0} \\
\lambda \geq 0,0 \leq \theta \leq 1
\end{array}\right.
\end{aligned}
$$

Malmquist index method was first proposed by Sten Malmquist, and further improved by Caves et al. (1982) and Fare and Grosskopf (1992). The paper uses this model to break up total factor efficiency into technical efficiency and technological progress changes to explore the main factor that contribute to the change of TFEE. The Malmquist index to decompose the total factor energy efficiency is shown as following:

$$
M_{0}\left(x^{t+1}, y^{t+1}, z^{t+1}, x^{t}, y^{t}, z^{t}\right)=E C H * T E C H=P E * S E * T E C H
$$


Where, $\mathrm{M}_{0}$ represents changes in total factor energy efficiency, which measure the change from period $t$ to $t+1$, if the value is greater than 1, it means the TFEE improved; if it equals to 1 indicates there is no change; otherwise, it is backward while the value of TEEE change is the part of Subtract $\mathrm{M}_{0}$ from 1 . ECH means technical efficiency changes; it means the contribution of technical efficiency to a DMU under the conditions. And if the index value is greater than 1 it means technical efficiency improved, if it equal to 1 indicates no change; otherwise it is backward. $\mathrm{ECH}=\mathrm{PE}^{*} \mathrm{SE}$, where PE means pure technical efficiency and $S E$ means scale efficiency. TECH means technology changes which represents the contribution of technology to TFEE here. If the value of TECH is greater than 1, then it means the contribution to TFEE is upward; otherwise, it is similar to that of ECH.

\section{Data description and variables}

Since the effects of natural disaster were considered as undesired output in the model, with the availability of data, the paper analyzed TFEE of 30 regions in China during the period of 2004-2010. Referred to indicator system of TFEE, capital stock, labor and energy consumption are chosen as input factors. As to the output indicators, we choose GDP and economic losses of natural disasters as output variables. According to importing order of DEAP software, the data description and variables are shown as follows:

- GDP is chosen as desired outputs. Original data was collected from China Statistical Yearbook of the year 2004 to 2010. As to data preprocessing of the indicator, the year 2004 is chosen as the base year to calculate data of 30 regions in the investigation period.

- Economic losses of natural disasters. Original data was collected from China Statistical Yearbook of 2004 to 2010 and Statistics Compilation of China within Sixty Years. In the paper economic losses of natural disasters was respected as undesirable output in the DEA model. The methods to deal with undesirable outputs include negative output method, nonlinear data conversion method and linear data conversion method. In order to keep convex and linear relationship between the variables of the original data, this article uses linear data conversion method to deal with the undesired output. The principle of the linear method is a linear function of the data: $f(x)=v-x$, where $v$ a large enough positive number vector which can ensure that all outputs are still positive number after the transformation while $x$ is the variable of economic losses to natural disasters in the regions.

- Capital input. Scholars currently use capital stock as an input variable in DEA method with perpetual inventory method as its commonly used data processing method that capital stock equals to sum of the capital stock of previous year and the capital formation in the current year while excluding capital depreciation in the current year $(\mathrm{Li}, 2003)$. The paper takes this commonly used method as the data processing method, and takes 2004 as the base year for data processing in order to ensure consistency of statistics of the paper. The original data was collected from China Statistical Yearbook of 2004 to 2010.

- Labor input. Labor employment is regard as an input factor. Taking the availability of data into consideration, the data processing of labor employment is that labor employment variable equals to the average of the labor employment of the previous 
year and the current year. The original data was collected from China Statistical Yearbook of 2004 to 2010.

- Energy input. Energy Consumption of Regions represents the amount of energy input with original data collected from China Statistical Yearbook of 2004 to 2010.

\section{Empirical results}

\section{TEEF from CCR-DEA method}

Import the processed data into DEAP2.1 software, and to calculate the TFEE of 30 regions in China from 2004-2010 under CCR-DEA method considering the effects of natural disaster. The values of TFEE are shown as Table 1. As we can see the four regions Beijing, Shanghai, Guangdong, Hainan, Qinghai have the highest TFEE and their TFEE value is 1 in the investigation period. Hei Longjiang and Fujiang have some years stay in the frontier according to their value of TFEE during the period. Three regions have the lowest TFEE that is Nei Menggu, Shanxi and Chongqing, their TFEE values are all below the 0.65. As to three main areas of China, the value of TFEE is the east is higher than the central and the west, and is higher than that of the total, which is 0.870 . The TFEE value of the central areas and the west areas are below the average value of the total while the west has the lowest TFEE value.

Table1. Energy efficiency of the 30 regions from 2004 to 2010

\begin{tabular}{|c|c|c|c|c|c|c|c|c|}
\hline Regions & 2004 & 2005 & 2006 & 2007 & 2008 & 2009 & 2010 & Average \\
\hline Beijing & 1 & 1 & 1 & 1 & 1 & 1 & 1 & 1.000 \\
\hline Tianjin & 1 & 1 & 1 & 1 & 1 & 1 & 1 & 1.000 \\
\hline Hebei & 0.727 & 0.786 & 0.777 & 0.738 & 0.72 & 0.722 & 0.744 & 0.745 \\
\hline Shangxi & 0.799 & 0.741 & 0.709 & 0.691 & 0.69 & 0.638 & 0.632 & 0.700 \\
\hline NeiMenggu & 0.65 & 0.612 & 0.627 & 0.607 & 0.599 & 0.595 & 0.576 & 0.609 \\
\hline Liaonin & 0.749 & 0.795 & 0.745 & 0.705 & 0.547 & 0.683 & 0.678 & 0.700 \\
\hline Jilin & 0.84 & 0.806 & 0.65 & 0.603 & 0.584 & 0.589 & 0.592 & 0.666 \\
\hline HeiLongjiang & 1 & 1 & 1 & 0.864 & 0.838 & 0.721 & 0.78 & 0.886 \\
\hline Shanghai & 1 & 1 & 1 & 1 & 1 & 1 & 1 & 1.000 \\
\hline Jiangsu & 0.891 & 0.833 & 0.839 & 0.844 & 0.781 & 0.818 & 0.82 & 0.832 \\
\hline Zhejiang & 0.872 & 0.903 & 0.903 & 0.902 & 0.853 & 0.886 & 0.886 & 0.886 \\
\hline Anhui & 0.845 & 0.858 & 0.839 & 0.8 & 0.775 & 0.819 & 0.832 & 0.824 \\
\hline Fujian & 1 & 0.882 & 0.873 & 0.852 & 0.78 & 0.77 & 0.782 & 0.848 \\
\hline Jiangxi & 0.751 & 0.804 & 0.782 & 0.787 & 0.788 & 0.779 & 0.827 & 0.788 \\
\hline Shandong & 0.679 & 0.749 & 0.761 & 0.761 & 0.775 & 0.741 & 0.732 & 0.743 \\
\hline Henan & 0.754 & 0.771 & 0.724 & 0.652 & 0.628 & 0.575 & 0.583 & 0.670 \\
\hline Hubei & 0.732 & 0.806 & 0.793 & 0.765 & 0.75 & 0.75 & 0.768 & 0.766 \\
\hline Hunan & 0.873 & 0.907 & 0.874 & 0.841 & 0.758 & 0.762 & 0.748 & 0.823 \\
\hline Guangdong & 1 & 1 & 1 & 1 & 1 & 1 & 1 & 1.000 \\
\hline Guangxi & 0.92 & 0.89 & 0.828 & 0.74 & 0.721 & 0.603 & 0.589 & 0.756 \\
\hline Hainan & 1 & 1 & 1 & 1 & 1 & 1 & 1 & 1.000 \\
\hline Chongqin & 0.628 & 0.623 & 0.62 & 0.591 & 0.527 & 0.719 & 0.755 & 0.638 \\
\hline Sichuan & 0.809 & 0.802 & 0.777 & 0.743 & 0.667 & 0.721 & 0.756 & 0.754 \\
\hline Guizhou & 0.752 & 0.772 & 0.802 & 0.778 & 0.823 & 0.852 & 0.852 & 0.804 \\
\hline Yunnan & 0.771 & 0.666 & 0.653 & 0.679 & 0.854 & 0.688 & 0.563 & 0.696 \\
\hline Shaanxi & 0.626 & 0.673 & 0.631 & 0.623 & 0.57 & 0.619 & 0.633 & 0.625 \\
\hline Gansu & 0.9 & 0.842 & 0.865 & 0.824 & 0.696 & 0.811 & 0.843 & 0.826 \\
\hline
\end{tabular}




\begin{tabular}{ccccccccc} 
Qinghai & 1 & 1 & 1 & 1 & 1 & 1 & 1 & 1.000 \\
Ningxia & 0.901 & 0.906 & 0.905 & 0.904 & 0.927 & 0.885 & 0.936 & 0.909 \\
Xinjiang & 0.695 & 0.721 & 0.708 & 0.733 & 0.815 & 0.777 & 0.759 & 0.744 \\
East & 0.904 & 0.904 & 0.888 & 0.867 & 0.837 & 0.841 & 0.847 & 0.870 \\
Cental & 0.792 & 0.815 & 0.787 & 0.756 & 0.732 & 0.721 & 0.732 & 0.762 \\
West & 0.787 & 0.773 & 0.765 & 0.747 & 0.745 & 0.752 & 0.751 & 0.760 \\
Total & 0.839 & 0.838 & 0.823 & 0.801 & 0.782 & 0.784 & 0.789 & 0.808 \\
\hline
\end{tabular}

As it can be seen from the change of TFEE values in the calendar year during the investigation period, as shown in Fig. 4, the values of TFEE of 30 regions are all have ups and downs over the years. And the TFEE values of the regions which belong to the highest TFEE groups remain stable over time. TFEE values of regions with years have the point on the frontier and that of regions with the lowest TFEE values are changing greater than other regions, and the values are on the trend of decreasing.

TFEE values that considering the effects of natural disasters appears the inflection point in 2008. In this year, some regions suffered a big TFEE change, and the changes among them sometimes are opposite. Regions that suffer the most and frequent natural disasters in 2008 such as Chongqing, Sichuan, Gansu and other regions have a sharp declining in the value of TFEE. At the same time, the TFEE values of regions like Yunnan, Ningxia, Guizhou and Xinjiang rise in 2008 which suffered natural diasters in the early monthes of 2008 and affected by the disasters in certain extent. Considered with the information of regions affected by natural disasters and TFEE of 30 regions from 2004 to 2010 in Fig. 4, the paper find it that TFEE considering the effects of natural disasters can better reflect the value of TEFF in each region.

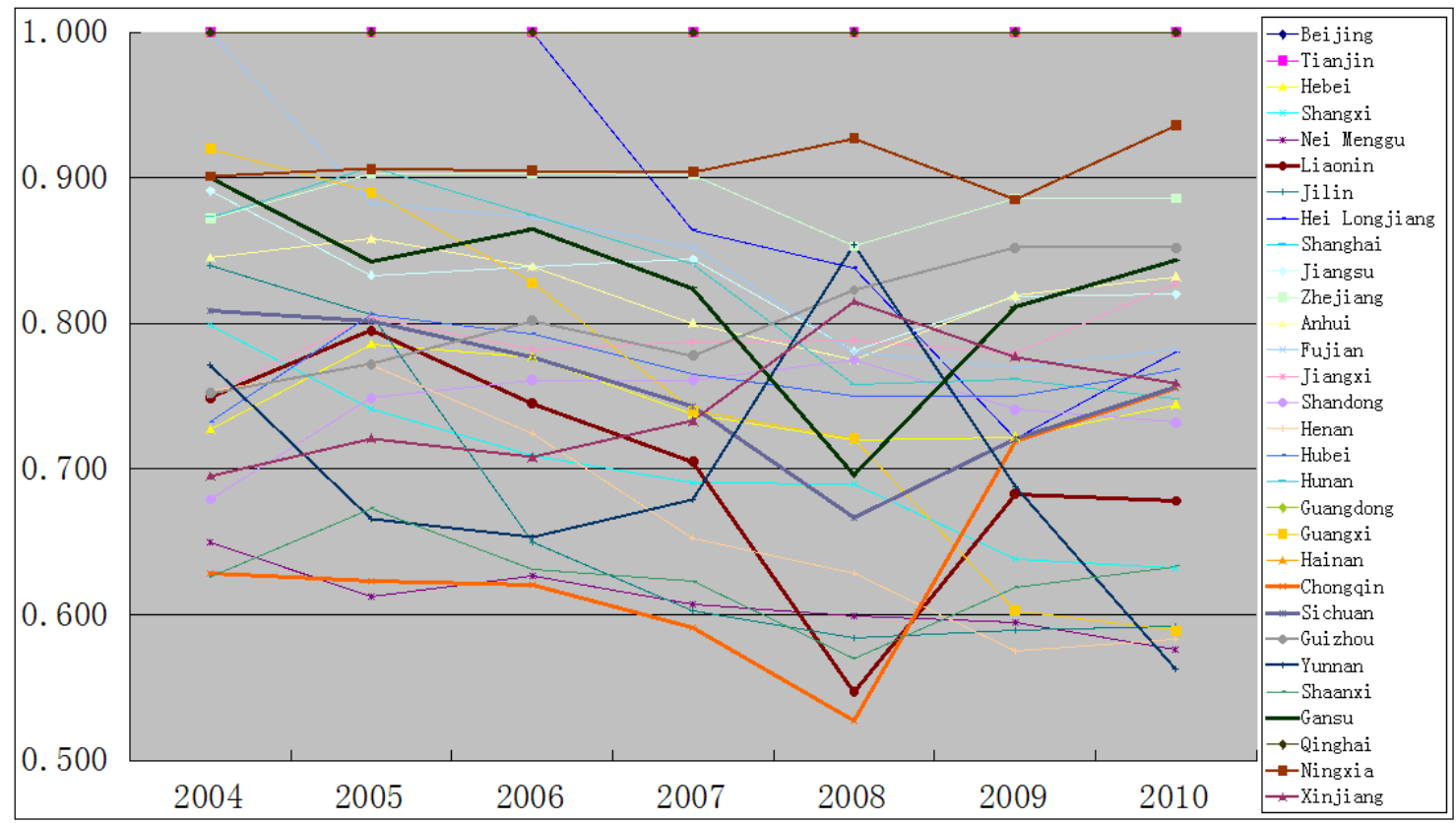

Figure 4. Total factor Energy efficiency of 30 regions from 2004 to 2010 


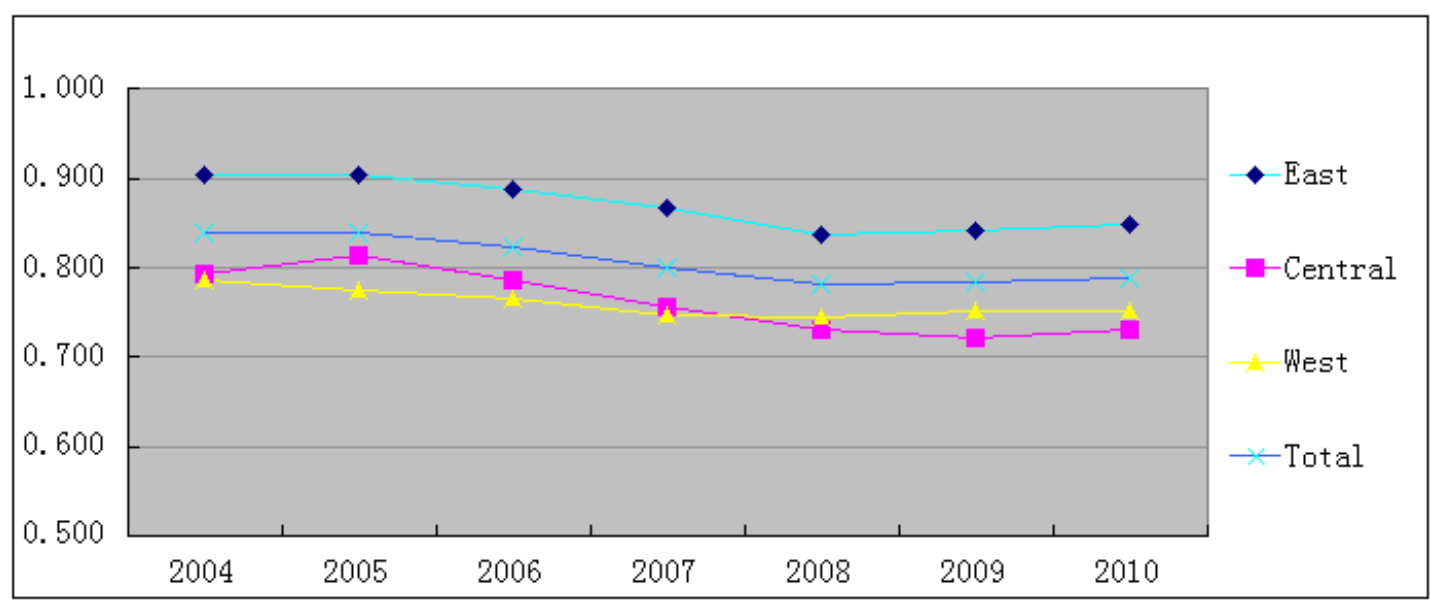

Figure 5. TFEE of the east, central, west and total

From a regional perspective, the TFEE value of east area in 2004-2010 has been in a downward trend, as shown in Fig. 5, and the central area has the same trend of TFEE value in the period, while the west area experienced TFEE value declines first and rises after, but the overall TFEE value change in west area is at a low extent that is consistent with the overall downward trend of TFEE in China during 2004-2010. The declining of TFEE value in the east area in consistent with the forecast that TFEE of China during 2004 to 2010 would on a downward trend of researchers in China like Wei and Shen (2007). As the similarity and time lag of the development of the central areas and the east areas, the central areas experienced TFEE value rises in 2004-2005, and have a downward trend of TFEE after 2005 similar to that of the east. Thus, the TFEE of three main areas of China during the year 2004 to 2010 have regional differences while a certain convergence with the development of these regions.

From the above analysis, the there still have problems to view the changes of regions easily from all the TFEE information of the regions. Thus, the paper uses SPSS software to do cluster analysis of TFEE of all the regions to find out the rangeability of TFEE in these regions and the possible groups of them according to their TFEE changes. With the between-group linkage method, three main clusters were generated according to the cluster result by SPSS software, as shown in Fig. 6, and we define this three clusters as high TFEE group, intermediate TFEE group and low TFEE group.

As it can be seen from Fig. 6, Beijing, Tianjin, Shanghai, Guangdong, Hainan and Qinghai regions belongs to high TFEE group. Inner Mongolia, Shaanxi, Chongqing, Shanxi, Henan, Jilin, Liaoning, Guangxi and Yunnan belongs to low TFEE groups. Other regions like Jiangxi, Guizhou, Shandong, Heilongjiang and so on are belongs to intermediate TFEE group. Thus, we can come to the conclusion that the changes of TFEE of different regions have some similarities among some regions though the changes of different regions are different to each other. According to the finding above, the paper advises that the government can have its strategies as to design regional developing policy to improve TFEE of regions according to its TFEE groups. For example, the government can put more attention on the low TFEE regions, encourage them to joint strength, and encourage them to learn from experience and technology of regions belongs to high TFEE group. As to high TFEE group, encourage them to share knowledge and technology to other regions, and to create powerful alliances with its members in the same group. 


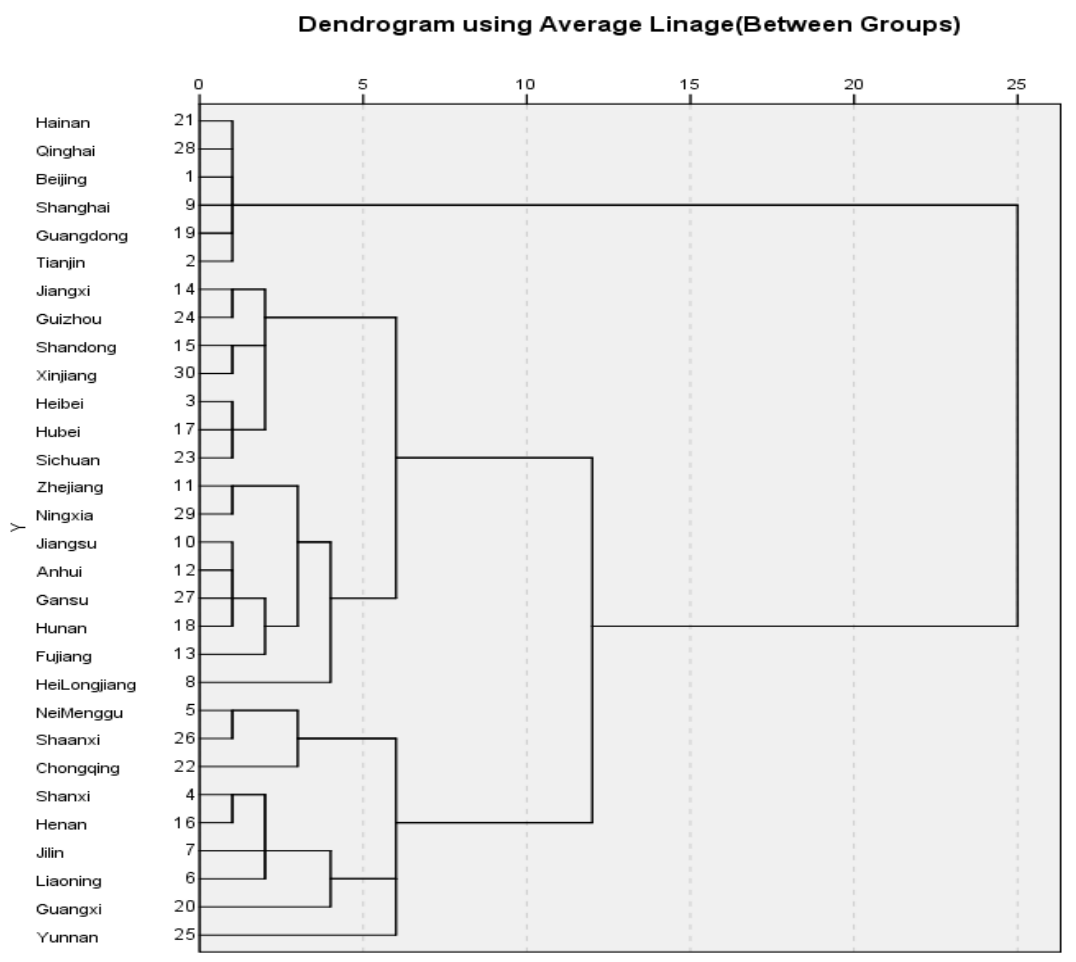

Figure 6. Dendrogram of TFEE Cluster analysis

Note: The division of east, central and west area is according to China Statistical Yearbook of 2011. The east area includes Beijing, Tianjin, Hebei, Shanghai, Jiangsu, Zhejiang, Fujian, Shandong, Guangdong, Hainan, Liaoning, Jilin and Heilongjiang regions; Anhui, Jiangxi, Henan, Hubei, Hunan and Shanxi are belongs to the central area whle the west area includes regions like Nei Menggu(Inner Mongolia), Guangxi, Chongqing, Sichuan, Guizhou, Yunnan,

Shaanxi, Gansu, Qinghai, Ningxia and Xinjiang.

\section{TEEF analysis with Malmqusit Index}

To further understand the differences of TFEE in different regions and years, the paper uses Malmquist index to decompose TFEE of different regions and years to expolre the contribution and status of technology efficiency and technology changes. With the panel data of 30 regions from 2004-2010, the paper uses the DEAP 2.1 software to do malmquist index analysis, and calculates the values of $E C H, T E C H$ and so on, as shown in Table 2 and Table 3, under two situation: not considering the effects of natural disasters and considering the effects of natural disasters. The overall trend of TFEE changes of 30 regions in the investigation period, as shown in Table 2, is in the form of recessionis no mater considering the effects of natural disasters or not when takes the average TFEE value into consideration which is 0.975 and 0.987 . In the consideration of not considering the effects of natural disasters, the TFEE of 30 regions in China appeared a positive growth in 2005 and 2008 while that in other years are dropped. When take the effects of natural disasters into consideration, all years' TFEE of 30 regions are declining in the investigation period. Thus, the paper comes to the conclusion that the TFEE considering the effects of natural disasters can better reflect the energy efficiency of China that the TFEE of 30 regions in China in the investigation period is on the downward trend. 
Table 2. Decomposition of TFEE of the year 2004 to 2010

\begin{tabular}{ccccccccccc}
\hline \multirow{2}{*}{ Year } & \multicolumn{3}{l}{ Not Considering Natural Disaster Effects } & \multicolumn{3}{c}{ Considering Natural Disaster Effects } \\
\cline { 2 - 11 } & ECH & TECH & PE & SE & TFEE & ECH & TECH & PE & SE & TFEE \\
\hline 2005 & 1.018 & 0.95 & 1.003 & 1.016 & 0.967 & 1.001 & 0.961 & 1.018 & 0.982 & 0.961 \\
2006 & 0.975 & 1.012 & 0.98 & 0.995 & 0.986 & 0.98 & 0.995 & 0.984 & 0.995 & 0.975 \\
2007 & 0.972 & 1.034 & 0.973 & 0.999 & 1.005 & 0.972 & 1.021 & 0.95 & 1.023 & 0.992 \\
2008 & 0.955 & 1.02 & 0.979 & 0.975 & 0.974 & 0.972 & 0.991 & 1.007 & 0.965 & 0.963 \\
2009 & 0.999 & 0.988 & 1.005 & 0.994 & 0.987 & 1.005 & 0.971 & 0.98 & 1.026 & 0.976 \\
2010 & 1.003 & 0.999 & 1.003 & 0.999 & 1.002 & 1.004 & 0.979 & 1.008 & 0.997 & 0.983 \\
average & 0.987 & 1 & 0.99 & 0.996 & 0.987 & 0.989 & 0.986 & 0.991 & 0.998 & 0.975 \\
\hline
\end{tabular}

From the perspective of technical efficiency change (ECH), as shown in Table 2, changes in the magnitude of technical efficiency are different under the conditions of considering the effects of natural disasters or not considering the effects of natural disasters. The changes of technical efficiency is relatively smaller when considering the effects of natural disasters, and the technical efficiency appears positive growth in 2005, 2009 and 2010. The technical efficiency of China's TFEE showed fluctuating trend changes in the investigation period. From the pure technical efficiency changes (PE) in Table 2, we can see that management efforts on Chinese energy utilization is relatively insufficient during 2004-2010; and the scale efficiency (SE) value shows that the allocation structure of investment elements is irrational of the year 2005, 2006 and 2010 whose se value less than 1, which indicating that the adjustments of the allocation structure of investment elements will improve TFEE in China. From the perspective of technological progress changes (Tech). TFEE of 2004 to 2010 is less than one except the year 2007 in the case of considering the effects of natural disasters while the TFEE values of 2006-2008 are greater 1, others remaining below 1, when not considering the effects of natural disasters. Combined with the fact that technological progress changes is one of the factor contribute to the changes of TFEE, we can see that the low energy efficiency of china is constrained by technology. With the changes of TFEE under the two condition above, the paper comes to the conclusion that the contribution of technological progress is relatively lower to TFEE of regions in China when considering the effects of natural disasters, thus it's important to rely on technological progress to improve TFEE of China.

As to decomposition of TFEE of different regions, as shown in Table 3, only Beijing, Tianjin, Shanghai, Zhejiang, Jiangsu, Jiangxi, Shandong and Chongqing regions have TFEE growth in the case of considering the effects of natural disasters during the period of 2004-2010, Shanghai has the highest TFEE reaching at 1.047, while other regions are on declining trend. As shown in Table 3, the valued of Shanghai's technological progress is the highest which equals to that of TFEE, 1.047. This explains that technological progress is the main factor of TFEE when considering the effects of natural disasters, thus, other regions can learn from the experience of Shanghai, Beijing, Tianjin and other high TFEE regions to improve the TFEE of their own regions by improving the contribution of technological progress.

As to the perspective of total country, the average value of TFEE, ECH,TECH, PE and SE of 30 regions in China during 2004-2010 are 0.987, 0.987, 1, 0.99 and 0.996 when not considering the effects of natural disasters while that in the case of considering the effects of natural disasters are $0.975,0.989,0.986,0.991$ and 0.998 . 
The contribution of technological progress decreased clearly when taked the effects of natural disasters into consideration while other variables hade various weak growth in this condition which showed that the contribution of technological progress to TFEE was lower in this case once again. Combined with the analysis of the contribution of technological progress to TFEE under the two cases, the paper found out that technological progress is a double-edged sword which can improve energy efficiency in human practice, but also can result to the frequent occurred natural disasters that have negative effect on the environment and human production activities. Thus, when the Government increased investment in science and encourage technological innovation to improve energy efficiency, they should focus on the double-edged nature of technologies and its rational use, not only consider the positive role of technological progress, but also taking adversely affect into account that the application of technology will hinder the development of the sustainable development of environment and society. In the case of considering the effect of natural disasters, the average value of TFEE decreased to 0.975 , with an average growth rate of $-3.75 \%$, indicating that excessive use of resources and frequent occurred natural disasters hindered China's energy efficiency resulting in energy resources waste and loss.

Table 3. Decomposition of regional TFEE

\begin{tabular}{|c|c|c|c|c|c|c|c|c|c|c|}
\hline \multirow{2}{*}{ Regions } & \multicolumn{5}{|c|}{ Not Considering Natural Disaster Effects } & \multicolumn{5}{|c|}{ Considering Natural Disaster Effects } \\
\hline & $\mathrm{ECH}$ & TECH & $\mathrm{PE}$ & SE & TFEE & $\mathrm{ECH}$ & TECH & $\mathrm{PE}$ & SE & TFEE \\
\hline Beijing & 1 & 1.044 & 1 & 1 & 1.044 & 1 & 1.036 & 1 & 1 & 1.036 \\
\hline Tianjin & 1.014 & 1.05 & 1 & 1.014 & 1.065 & 1 & 1.034 & 1 & 1 & 1.034 \\
\hline Hebei & 1.002 & 0.978 & 1.004 & 0.998 & 0.98 & 1.004 & 0.975 & 1.006 & 0.998 & 0.979 \\
\hline Shangxi & 0.956 & 0.988 & 0.962 & 0.994 & 0.944 & 0.962 & 0.985 & 0.962 & 1 & 0.947 \\
\hline NeiMenggu & 0.991 & 1.011 & 0.98 & 1.011 & 1.001 & 0.98 & 1 & 0.98 & 1 & 0.98 \\
\hline Liaonin & 0.987 & 1.007 & 0.984 & 1.004 & 0.994 & 0.983 & 1 & 0.984 & 1 & 0.983 \\
\hline Jilin & 0.943 & 1.022 & 0.945 & 0.998 & 0.964 & 0.943 & 1.012 & 0.945 & 0.998 & 0.954 \\
\hline HeiLongjian & 0.956 & 0.988 & 0.959 & 0.996 & 0.944 & 0.959 & 0.981 & 0.962 & 0.997 & 0.941 \\
\hline Shanghai & 1 & 1.05 & 1 & 1 & 1.05 & 1 & 1.047 & 1 & 1 & 1.047 \\
\hline Jiangsu & 0.986 & 1.025 & 1.012 & 0.975 & 1.011 & 0.986 & 1.025 & 1.019 & 0.967 & 1.011 \\
\hline Zhejiang & 1.003 & 1.024 & 1.009 & 0.995 & 1.028 & 1.003 & 1.024 & 1.01 & 0.993 & 1.027 \\
\hline Anhui & 0.995 & 0.976 & 0.997 & 0.998 & 0.971 & 0.997 & 0.968 & 1 & 0.998 & 0.965 \\
\hline Fujian & 0.96 & 1.032 & 0.96 & 0.999 & 0.99 & 0.96 & 1.027 & 0.96 & 1 & 0.986 \\
\hline Jiangxi & 1.01 & 1.012 & 1.017 & 0.994 & 1.023 & 1.016 & 0.99 & 1.017 & 0.999 & 1.006 \\
\hline Shandong & 1.013 & 1 & 1.025 & 0.988 & 1.013 & 1.013 & 0.998 & 1.025 & 0.988 & 1.011 \\
\hline Henan & 0.958 & 0.985 & 0.958 & 1 & 0.944 & 0.958 & 0.979 & 0.958 & 1 & 0.938 \\
\hline Hubei & 1.006 & 0.976 & 1.008 & 0.998 & 0.982 & 1.008 & 0.968 & 1.008 & 1 & 0.976 \\
\hline Hunan & 0.973 & 0.975 & 0.975 & 0.998 & 0.948 & 0.975 & 0.967 & 0.975 & 1 & 0.942 \\
\hline Guangdong & 1 & 0.996 & 1 & 1 & 0.996 & 1 & 0.995 & 1 & 1 & 0.995 \\
\hline Guangxi & 0.934 & 0.999 & 0.929 & 1.005 & 0.932 & 0.928 & 0.987 & 0.929 & 1 & 0.917 \\
\hline Hainan & 0.974 & 1.021 & 1 & 0.974 & 0.995 & 1 & 0.926 & 1 & 1 & 0.926 \\
\hline Chongqin & 1.02 & 0.99 & 1.031 & 0.989 & 1.01 & 1.031 & 0.971 & 1.039 & 0.992 & 1.001 \\
\hline Sichuan & 0.987 & 0.977 & 0.989 & 0.998 & 0.964 & 0.989 & 0.972 & 0.989 & 1 & 0.961 \\
\hline Guizhou & 1.013 & 0.975 & 1.021 & 0.992 & 0.988 & 1.021 & 0.949 & 1.021 & 1 & 0.969 \\
\hline Yunnan & 0.944 & 0.977 & 0.95 & 0.994 & 0.922 & 0.949 & 0.963 & 0.95 & 1 & 0.914 \\
\hline Shaanxi & 1 & 0.985 & 1.002 & 0.998 & 0.985 & 1.002 & 0.971 & 0.985 & 1.018 & 0.973 \\
\hline
\end{tabular}




\begin{tabular}{ccccccccccc} 
Gansu & 0.98 & 0.975 & 0.989 & 0.99 & 0.956 & 0.989 & 0.949 & 0.989 & 1 & 0.939 \\
Qinghai & 1 & 0.98 & 1 & 1 & 0.98 & 1 & 0.922 & 1 & 1 & 0.922 \\
Ningxia & 0.989 & 0.993 & 1.003 & 0.986 & 0.981 & 1.006 & 0.99 & 1.017 & 0.989 & 0.996 \\
Xinjiang & 1.015 & 1.002 & 1.015 & 1 & 1.017 & 1.015 & 0.983 & 1.015 & 1 & 0.997 \\
Average & 0.987 & 1 & 0.99 & 0.996 & 0.987 & 0.989 & 0.986 & 0.991 & 0.998 & 0.975 \\
\hline
\end{tabular}

\section{Conclusions}

Currently, energy has become the focus of concern and problems to be solved in various countries and regions as energy shortage is exacerbated by energy wastage and low energy efficiency, and has become a major crisis that affects the quality of people's daily life. Therefore improving energy efficiency has become one way to solve the energy crisis. In this paper, the paper analyzed TFEE of 30 regions in China with DEA and Malmquist index method from the perspective of static and dynamic time series to do quantitative analysis and evaluation on it, and summarized the conclusions and recommendations of the paper shown as follows :

- From the static time series viewpoint, we can find out that the TFEE value of five regions of Beijing, Tianjin, Shanghai, Guangdong and Qinghai are equals to 1 which mens the TFEE of these five regions are efficient, thus other regions should learn from the experience of these five regions on energy efficiency to adjust their investment allocation of resources. From the analysis of regional TFEE, we come to the conclusion that Beijing, Tianjin, Shanghai, Zhejiang, Jiangsu, Jiangxi, Shandong and Chongqing regions have TFEE growth in the case of considering the effects of natural disasters during the period of 2004-2010 which indicating that these regions have made certain achievements in energy use in case of considering natural disasters effects. Beijing, Tianjin, Shanghai and Zhejiang regions mainly depend on the technological progress, which provide reference for other regions to improve their TFEE by learning and introducing advanced technology, and emphasizing on the role of science and technology elements while relying on advances in technology to improve TFEE in all regions.

- From the dynamic time series perspective to analyze TFEE, the paper found out that the TFEE of 30 regions in China from 2004 to 2010 is on the trend of downward considering the effects of natural disasters which indicating that with the rapid development of economy and frequent occurred natural disasters in China, China's energy efficiency declined. The reason to the declining trend is that the contribution of technological progress is lower when considering the effects of natural disasters. Thus, the paper came to the conclusion that technological backwardness of many regions in China is the constraints of TFEE and the doubleedged nature of technological progress also related to the decreasing of TFEE. Thus, to improve the TFEE of regions in China, the government not only need to increase investment in science and encourage technological innovation, but also should focus on the double-edged nature of technologies and standardize the use of technology by considering the positive role of technological progress and taking adversely affect into account that the application of technology will hinder the development of the sustainable development of environment and society. The paper also found out that the total TFEE shows no positive growth during the period of 2004-2010. Though, the recession of technological process is a main factor result to the declining trend of TFEE, the technical efficiency also need to be improved, 
thus, the improvement on energy management is a practical way to improve energy efficiency of China.

- From the regional development perspective, the development of TFEE of the east, central and the west is imbalanced and uneven. Therefore, strengthening interregional cooperation, sharing knowledge and technology, and rational application of science and technology, especially for regions that are relatively economically backward and frequently disaster-prone, will benefit the common development of different regional areas, and the study and rational application of science and technology will effectively improve the energy efficiency issues in the long run.

China's energy efficiency problems such as regional development imbalance, also exist in developing countries or the worldwide. Thus, the paper provides a reference for developing countries or even all the world to solve environmental and energy issues.

Acknowledgements. The research was sponsored by the National Natural Science Foundation of China (No. 71363044) and by Soft Science Research Plan of Science and Technology Department of Jiangxi Province (No. 20161BBA10046).

\section{REFERENCES}

[1] Azadeh, A., Amalnick, M. S., Ghaderi, S. F., Asadzadeh, S. M. (2007): An integrated DEA PCA numerical taxonomy approach for energy efficiency assessment and consumption optimization in energy intensive manufacturing sectors. - Energy Policy 35: 3792-3806.

[2] Boyd, G. A., Pang, J. X. (2000): Estimating the linkage between energy efficiency and productivity. - Energy Policy 28(5): 289-296.

[3] Caves, D. W., Christensen, L. R., Diewert, W. E. (1982): The economic theory of index numbers and the measurement of input, output and productivity. - Econometrics 50: 1393-1414.

[4] Coelli, T. J. (1996): A guide to deap version 2.1: A Data Envelopment Analysis (Computer) Program,Department of Econometrics, University of New England, Armidale, Australia.

[5] Cui, Q., Kuang, H. B., Wu, C. Y. (2014): The changing trend and influencing factors of energy efficiency: The case of nine countries, Energy 4: 1026-1034.

[6] Fan, H., Zhou, D. Q. (2012): On the total factor energy efficiency with undesirable outputs in China. - Journal of applied statistics and management 31(6): 1084-1096.

[7] Fare, R., Grosskopf, S. (1992): Malmquist productivity indexes and Fisher ideal indexes. - The Economic Journal 102(410): 158-160.

[8] Farrell, M. J. (1957): The measurement of productive efficiency. - Journal of the Royal Statistical Society (Series A General) 120(3): 253-290.

[9] Honma, S., Hu, J. L. (2008): Total-factor energy efficiency of regions in Japan. - Energy Policy 36(2): 821-833.

[10] Hu, J. L., Wang, S. C. (2006): Total-factor energy efficiency of regions in China. Energy Policy 34(17): 3206-3217.

[11] Kang, X. F., Zhang, H., Martins, V. (2016): Experimental study on thawing process fo frozen soil based on CT scanning. - Journal of Mechanical Engineering Research and Developments 39(2): 340-346.

[12] Li, K. W. (2003): China's capital and productivity measurement using financial resources. Center Discussion Paper No. 851. - Economic Growth Center, Yale University.

[13] Liu, Z. L. (2013): Enviromental Kuznets Curve: A new computational test and modeling. - IJACT 5(5): 551-558. 
[14] Martinez, C. I. P. (2011): Energy efficiency development in German and Colombian nonenergy-intensive sectors: a non-parametric analysis. - Energy Efficiency 4(1): 115-131.

[15] Mukherjee, K., (2008): Energy use efficiency in U.S. manufacturing: a nonparametric analysis. Energy Economics 1: 76-96.

[16] Newell, R. G., Jaffe, A. B., Stavins, R. N. (1998): The induced innovation hypothesis and energy- saving technological change. - Quarterly Jour-nal of Economics 114: 941-975.

[17] Samuels, G. (1984): Potential production of energy canefor fuel in the caribben. - Energy Progress 4: 249-251.

[18] Vlahinic-Dizdarevic, N., Segota, A. (2012): Total-factor energy efficiency in the EU countries. - Zbornik Radova Ekonomskog Fakulteta U Rijeci-Proceedings of Rijeka Faculty of Economics 30(2): 247-265.

[19] Wei, C., Shen, M. H. (2007): Energy efficiency and energyproductivity: a comparsion based on the panel databy province. - The Journal Quantitative and Techni-cal Economics 9: 110-121.

[20] Zhang, X. P., Cheng, X. M. (2011): Total-factor energy efficiency in developing countries. - Energy Policy 39(2): 644-650.

[21] Zou, G. F., Chen, L. M., Liu, W. (2013): Measurement and evaluation of Chinese regional energy efficiency based on provincial panel data. - Mathematical and Computer Modellingy 58(5-6): 1000-1009. 